\title{
Planning Climate Change Adaptation Activities for Turkey
}

\author{
Aysegul Tanik and Deniz Tekten
}

\begin{abstract}
Turkey, representing a developing country, is on the way to plan its adaptation activities within the context of climate change effects. This study initially proposes the main sectors under which associated adaptation practices and related action plans be listed according to the country's needs. Turkey bears 25 river basins out of which 17 are coastal watersheds. Another important characteristic of the country is that it stands variable and different climatic conditions as it is located at a transient region between Europe and Asia continents. As such, sectoral-based adaptation action plans against climate change will differ in the basins of the country according to sectoral vulnerability analyses. Upon detailed investigation of sectoral-based adaptation action plans of 7 countries (Germany, France, Spain, Italy and Denmark from Europe, USA from America and Kenya from the Africa continent), 12 main sectors are selected for Turkey and urgent climate change adaptation actions are stated under each sector. The selection criteria involved geographical location and features of Turkey, prevailing environmental problems, climatic conditions, land-use activities, urbanization level, technical and economic development level together with socio-economic structure and financial development of the country.
\end{abstract}

Index Terms-Adaptation practices, climate change, EU strategies, sectoral based action plans, Turkey.

\section{INTRODUCTION}

Adapting to climate change and minimizing its possible effects has become a real necessity in today's world including Turkey that represents a developing country. Climatic changes have already been observed in Turkey and they seem to increase over the coming decades. To summarize, Turkey is projected to experience [1]

- Temperature increases everywhere at all seasons; but the increases are expected to be higher in summer than winter,

- Decreases in annual precipitation amounts in the southern parts of Turkey, and possible slight increases in the northeast,

- More intense precipitation events, increasing the risks of fluvial and pluvial flooding together with landslides,

- Increased intensity and duration of droughts and hot spells, leading to increased water stress,

- Rising sea levels, increasing the risks of flooding in the low-lying areas of river deltas and coastal cities.

Similar to Turkey's situation, almost all the nations in the world will most likely suffer more from the impacts of climate change in the future. Therefore, there is a real necessity to

Manuscript received March 15, 2018; revised July 13, 2018

A. Tanik is with the Istanbul Technical University (ITU), Faculty of Civil Engineering, Department of Environmental Engineering, Ayazaga Campus, 34469, Maslak-Istanbul, Turkey (e-mail: tanika@itu.edu.tr).

D. Tekten was with ITU during 2014-2016. She is now with Greif FPS Turkey Gebze, Kocaeli, Turkey (e-mail: deniz_tekten@ hotmail.com). develop methodologies for assessing the vulnerability of water resources most preferably at watershed scale in order to take precautions and protective measures before it is too late. These provisions to be considered are called 'adaptive measures and adaptation actions' that are required to be listed in a priority order for the attention of decision-makers.

A 'successful adaptation' must be in line with sector-specific indicators. The use of indicators is of high importance in informing and evaluating decision-making in the widest sense both for policy making and practice [2]. Adaptation to climate change is an improving and practicing process of strategies towards effective mitigation with the probable risks of climate change impacts. As referred for the first time in the $4^{\text {th }}$ IPCC Report [3], it is initially necessary to determine sectoral vulnerability. Vulnerability is a function of the exposure, sensitivity and adaptive capacity as depicted by IPCC. The evolution of approaches for assessing vulnerability has already become an emerging concept since the last few decades for climate science and policy. The historical development of conceptual ideas on this approach is well summarized by Füsell and Klein [4]. Climate change influences both exposure and sensitivity, and therefore, creates potential climate impacts, which in turn, increase vulnerability. Adaptive capacity including technological, socio-economic and educational capacities have the potential to reduce vulnerability. The relationship between these terminologies is expressed schematically in Fig. 1.

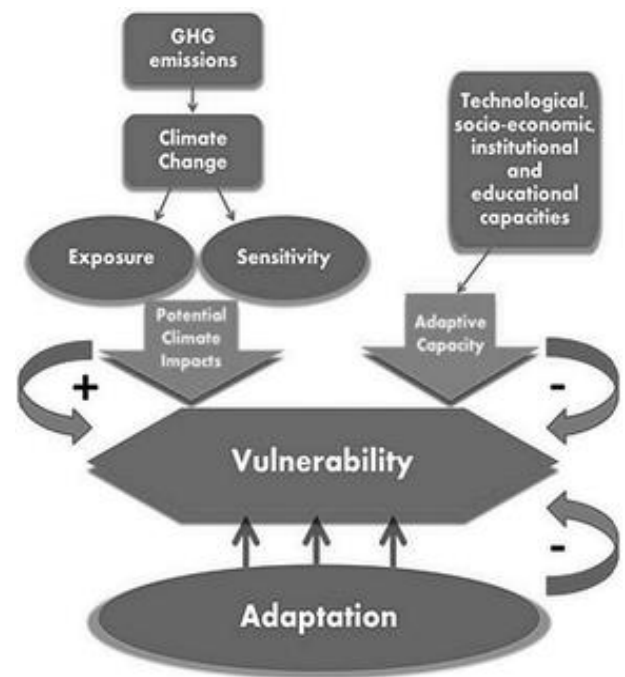

Fig. 1. Schematic diagram showing linkage between vulnerability, adaptation and climate impacts [5].

\section{COP21 AND SitUATION OF TURKEY}

Climate Change Environmental Convention (CCEC) has been put into force on 21 March 1994. The main target of this agreement was to reduce greenhouse gas (GHG) emissions and submit a solution opportunity for global heating problem 
of the world. This convention was signed by 191 countries and European Union (EU). Turkey, as a participatory country, was at the beginning taking place both in Annex-I and Annex-II of the convention However, upon its application in 2001, Turkey was removed from Annex-II as the country was at a transient condition [6]. Annex I countries were obliged to "adopt national policies and take corresponding measures on the mitigation of climate change" according to the Convention. These Parties were supposed to take the lead in fulfilling the objective of the Convention [7]. Since 1994, Conference of the Parties (COP) has met every year among which the well-known one was held at 1997 where Kyoto Protocol has been signed. Annex I countries, Annex II countries, and countries that were not listed in any of the annexes "non-Annex I" countries are shown in Figure 2. Annex I includes industrialised countries as well as many states of the former Soviet Union (the Economies in Transition, or EIT). Annex II is a further subset of Annex I; it includes only countries that were members of the OECD at the time the Convention was adopted. Thus, non-Annex I countries, which are the large majority, mostly correspond to developing countries.

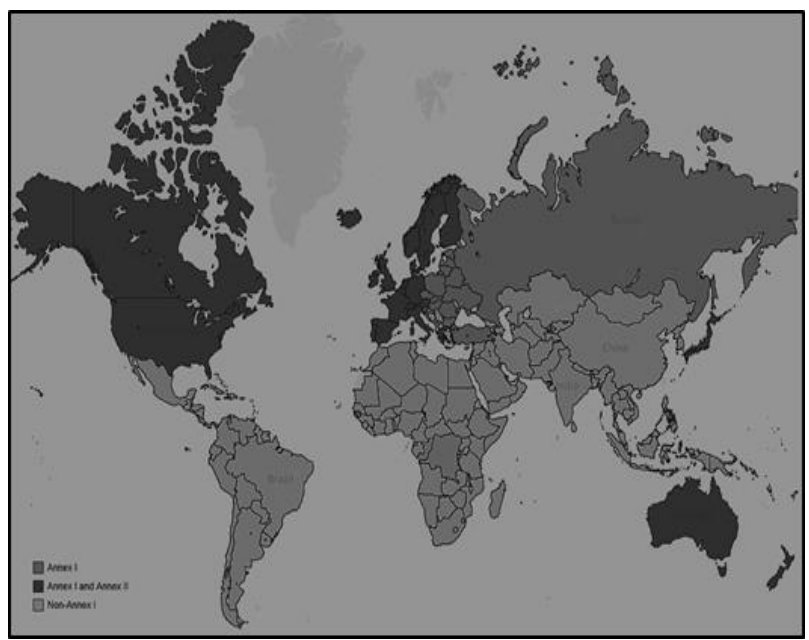

Fig. 2. The recent situation of the world regarding the Convention [7].

Turkey's GHG emissions (as $\mathrm{CO}_{2}$ equivalent) per capita increased by $122 \%$ in 2015 compared to the emissions in 1990. Emissions per capita were 6.07 tonnes in 2015, while it was 3.88 tonnes for the year 1990 [8]. This value is still low; but is increasing rapidly. It is $1 / 3$ of the OECD average and $1 / 2$ of EU. Turkey announced that it would reduce GHG emissions by up to $21 \%$ from the 'business-as-usual' level by 2030 [9]. As of today, Turkey supplies $20 \%$ of its energy need from renewable energy resources and targets to increase this ration to $30 \%$ by year 2030 . The country has also declared its National Climate Change Strategy Document in 2011 that covers the period of 2010-2023. The action plan based on this strategy document has also been completed in 2011.

Finally on $21^{\text {st }}$ of December 2015 at Paris, COP21 stated that the main target is to bring global warming below $2{ }^{\circ} \mathrm{C}$ compared to pre-industrialization period. Therefore, it was underlined that it is really the problem of USA and China as these are the leading countries contributing to highest carbon emission of the world. Intended Nationally Determined Contributions (INDC) of over 150 countries has been submitted at this meeting. The sum of commitments in this declaration indicated that the target of $2^{\circ} \mathrm{C}$ will not be fastened at the end of the century; it is foreseen that it will be $2.7^{\circ} \mathrm{C}$. In case no additional commitments are realized, it is expected that global warming will be more significant by around $4^{\circ} \mathrm{C}[10]$.

Turkey has committed to decrease the increase of emissions and not reduction of emissions. In other words, between years 1990-2013, GHG emissions annually increased by $3.9 \%$. As submitted in the main scenario analysis, this value was foreseen to be $5.7 \%$ increase per year till 2030 . However, the country committed to increase GHG emissions by $4.2 \%$ per year within the same projection period [11]. Quite a lot of scientific studies were cited in literature regarding the climatic situation of Turkey and the country's attempts towards setting policies within the past decade. Climate change in Turkey for the last half century has been thoroughly investigated by Turkish scientists [12]. Climate change simulations over climate zones of Turkey were assessed in 2014 [13] and climate change policy of the country during 1992-2015 was summarized in 2016 [14].

\section{Proposed Sectors for Sectoral AnAlysis}

Adaptation activities towards minimizing the adverse effects of climate change need to be based on sectors. Sectors to be considered varies from country to country as sensitivity factors vary a lot. Each country has its intrinsic concerns; and thus, selection of important and highly sensitive sectors to climate change relies on prioritization of the probable effects. In that sense, 12 main sectors listed in Table I were selected for Turkey following a thorough review of the situation and the corresponding sectors selected for 7 countries; namely Germany, France, Spain, Italy and Denmark from Europe, USA from America and Kenya from the Africa continent [15].

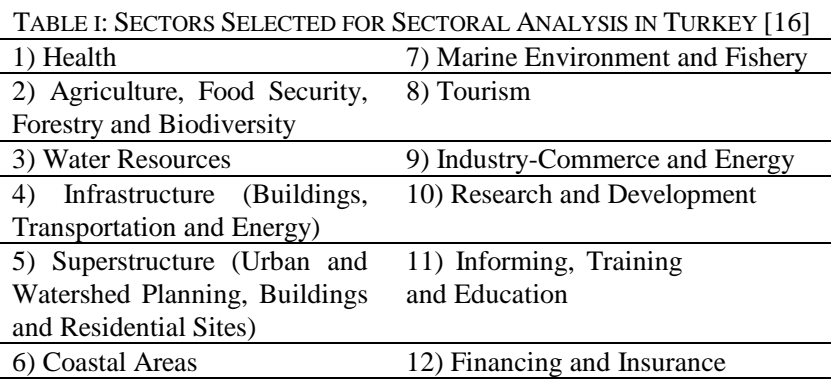

Selection criteria involved the geographical properties of the country, its location, environmental problems, climatic conditions, land-use activities, urbanization trend, technical and economic development level together with socio-economic structure and financial development level of Turkey.

Health is the underlying component of life and survival, and well-being of all the living organisms (human-animal-plantation) in the world basically rely on it. Impact of extreme weather events and climate change for human health was thoroughly reviewed recently [17], [18]. Therefore, it is the priority sector in every country as it is known that most of the infectious diseases pass through water; pathogenic illnesses are quite typical and widespread during 
summer months especially in areas where drought predominates as is the frequently observed case in the south-eastern part of Turkey.

Almost $50 \%$ of the country's land is devoted to agricultural activities according to 2015 FAOSTAT data [19]. Figure 3 shows the land-use/cover distribution of Turkey since 1961. It is clearly seen that agriculture is still the most important economic sector in the country. Figure 4, on the other hand, refers to the distribution of agricultural practices. As of 2015, $54 \%$ of agricultural land is arable land; while $38 \%$ is occupied by permanent meadows and pastures. The minority $8 \%$ is devoted to permanent crops. The two major sectors of the country, as seen from the figures, are agriculture and forestry. Turkey is suitable for afforestation due to its favourable climatic conditions. As well-known, there is a close linkage between precipitation and distribution of forests. Another sector that relates to both of these sectors is biodiversity. Therefore, this sector is also addressed as one of the sectors that have high potential of vulnerability towards climate change.

Both groundwater and surface water resources are prone to be affected from climate change in the future. Even though Turkey is auspicious in having a rich stream network in its region; its water potential is expected to be highly affected in the long run. Therefore, water resources are proposed to be a different and important sector to take place in the list of sectors.

A project on the climate change effects on the water resources of the country has been conducted between years 2013-2016 under the supervision of the Ministry of Forestry and Water Works of Turkey [20]. In this study, three global climate models; HadGEM2-ES, MPI-ESM-MR and CNRM-5.1 selected from CMIP5 database were run for simulating climate with a resolution of $10 \times 10 \mathrm{~km}$ till the end of this century. Reference period simulations of the global models were matched and compared with the monitored values. All the 3 global models were based on 2 scenarios; namely RCP4.5 and RCP8.5 [20]. The outputs of climate models were then utilized as input values in hydrological and hydraulic modelling parts. The results on the probable changes in water resources were evaluated based on the watersheds of the country.

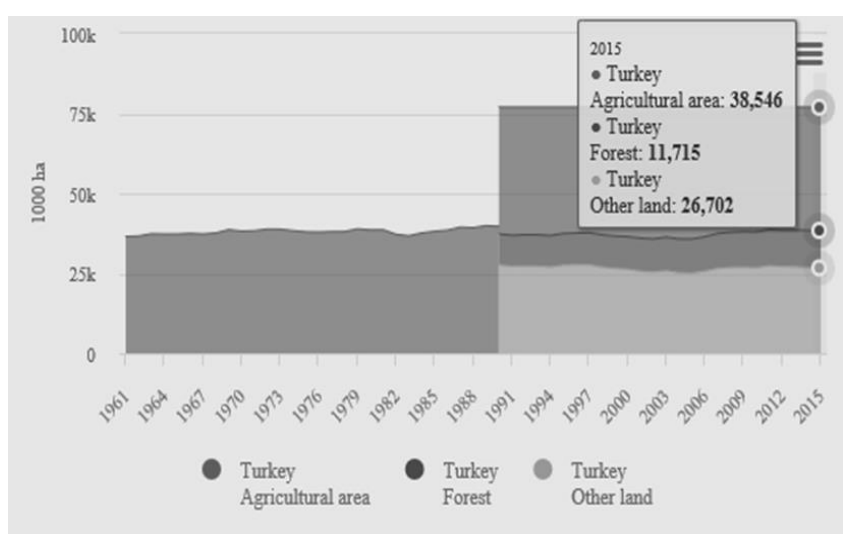

Fig. 3. Distribution of land-use/cover of Turkey [19].

Similarly, the hydrological simulations were also conducted under the 3 models and 2 scenarios. Therefore, the authorities, aware of probable changes of climate change on water resources, have put forth a valuable database that could be used by all the related parties while coping with the probable changes that might occur in future.

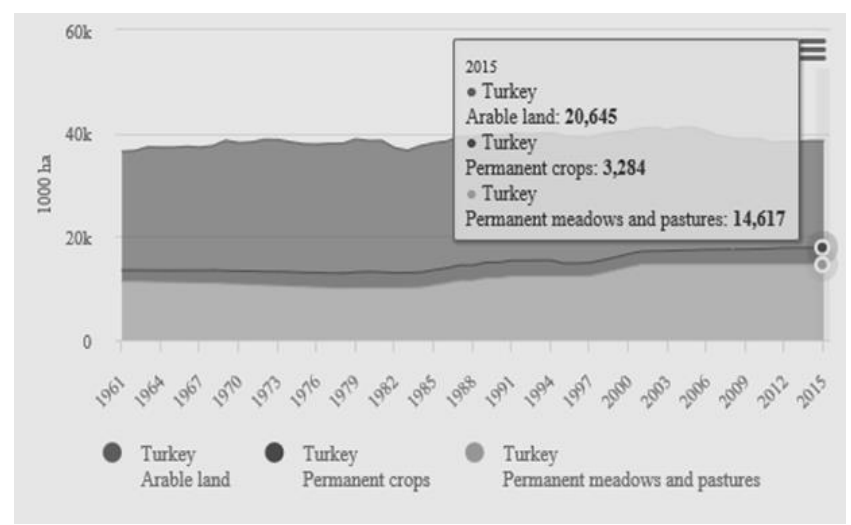

Fig. 4. Distribution of agricultural land in Turkey [19].

As Turkey is still a developing country, it has not yet completed its infrastructure needs consisting of buildings, energy and transportation. Thus, infrastructure is regarded as an important sector that seems to be highly impacted by climate change. This lack and/or incompleteness of infrastructural requirements lead to a significant gap among the occurrence of disasters and realization of mitigation actions towards rehabilitating the situations affected from extreme conditions. This concept was also underlined by the European Bank established for construction and development [21].

As such, various environmental problems are still experienced in Turkey regarding infrastructural works such as significant losses in electricity and water transmittance. It is also recommended that climate change effects of all sorts of transportation systems and networks like railways, highways, airports, harbours and marine transportation have to be evaluated under this sector. The conception of green infrastructure within the context of climate adaptation has been referred in many recently published articles [22], [23]. Even though there is still a high necessity for accelerating infrastructural developments, the speed of superstructure applications performs just the opposite due to rapid urbanization efforts in Turkey. The population increase and migration from the rural parts of the country towards urbanized regions is among the major reasons of this trend that finally results in more illegal, unplanned and irregular structures that necessitates proper urban and watershed planning with the fulfilment of infrastructure. Moreover, there appears a requisite for initiating pioneer studies considering appropriate material selection, resource utility, waste recycling, efficient use of water and energy, and less carbon emissions in individual buildings to minimize the probable effects of climate change. Urban transformation has become a popular trend particularly in the megacities; thus, in these new residential sites, climate change effects have not yet been sufficiently considered as depicted and analysed in a recently published book [24]. In that sense, superstructure is also addressed as another vital sector.

Turkey is surrounded by seas from the three sides. Like in many other coastal European countries [25], [26] and USA, coastal zone management [27], [28] has turned out to be an 
emerging topic regarding climate change. Sea level rise based on tidal effects, extreme precipitation ending in overflows and sea-land interaction are among the well-known natural occurrences and hazards. Majority of these incidents are due to climate change. Therefore, mitigation actions, emergency plans and early warning systems are among the proposed practices in the coastal areas. 17 watersheds out of 25 are coastal watersheds in Turkey as seen in Figure 5. This situation has put forth the significance of this sector which will be of concern only in the coastal watersheds. It is important to note at this point that Black Sea, Aegean Sea, Mediterranean Sea as well as the inner Sea of Marmara are geographically and climatically perform different characteristics.

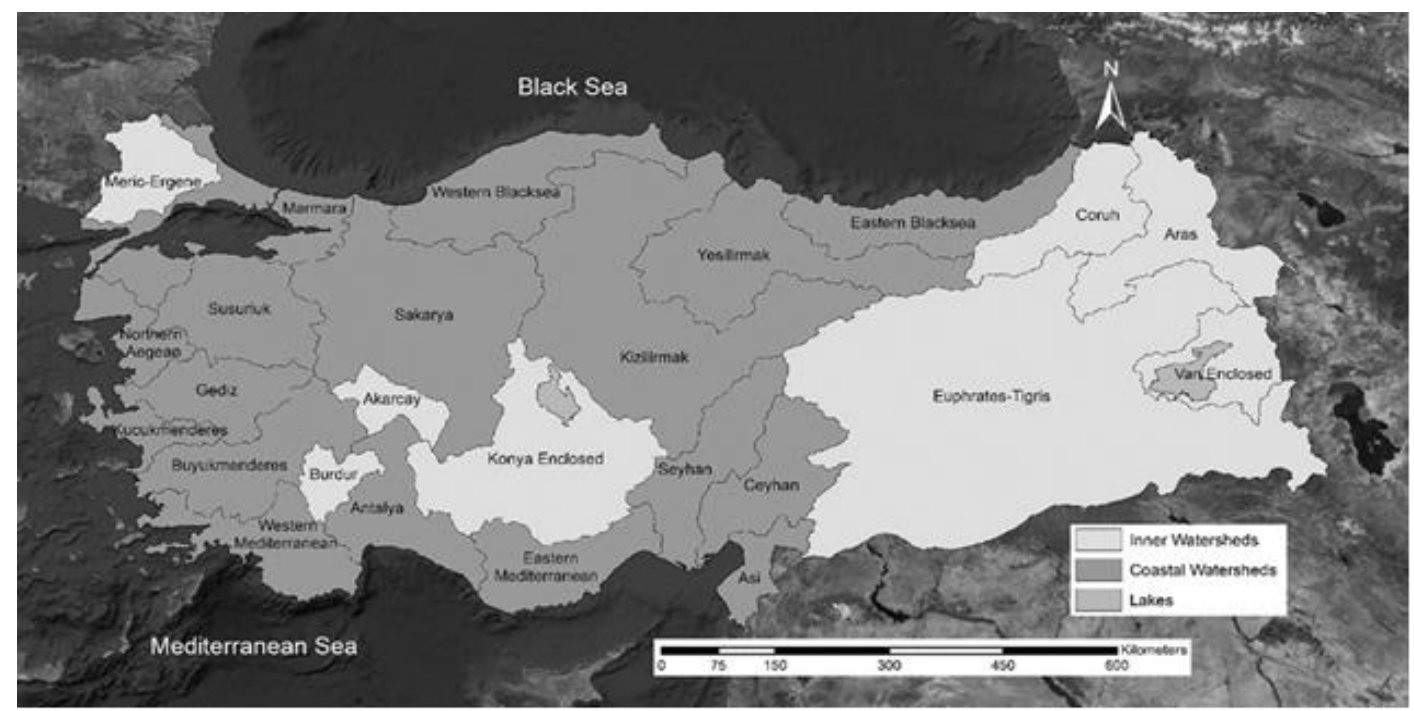

Fig. 5. Geographical location of the watersheds in Turkey.

Similarly, marine environment and fishery along the coastal watersheds are prone to climate change effects like sea temperature variation, pollution causing external factors, which in turn, cause changes in the sea life [29], [30]. This sector is also selected for Turkey as it directly relates to fishery which is an important economic sector in the country that is surrounded by seas from the 3 sides.

Turkey houses an important tourism potential especially in watersheds along the Aegean Sea and Mediterranean Sea. Long-lasting strategies must be developed in these vulnerable areas to convert the impacts of climate change to opportunities [31].

Additionally, inner watersheds also bear many protected and historical areas where tourism is of interest both for the national and international travellers. Precautions towards protection of these sensitive areas need to be considered beforehand through planning activities.

Success of the proposed sectors against the climate change risks and effects depend on the depth of research and development (R\&D) activities. Vulnerability analyses and technical results of the recent scientific studies need to be used in mitigation trials and efforts.

In parallel to $\mathrm{R} \& \mathrm{D}$; informatics, education and training activities on almost all the environmental topics and concerns, and sharing knowledge with public is expected to be realized in the short run. Introduction of adaptation activities against climate change effects to the central administrative units must be realized. Necessary capacity of related labour at the national, regional and local scale seems to be urgently employed. Therefore, R\&D together with information, education and training are regarded as the 2 other sectors that need to be considered among the proposed sectors for analysis.

Last but not the least, finance and insurance is recommended as the final sector to be considered. The first 9 sectors proposed may suggest and list urgent and long-term adaptation activities and even prioritization of them is possible. However, realization of these actions will require critical amount of funding; therefore, sufficient amount of money need to be allocated for adaptation attempts.

Planning of funding arrangements, developing policies and insurance costs will be required in the near future. In that sense, this sector is also considered.

\section{PROPOSED URGENT AdAPTATION ACTIONS FOR EACH SELECTED SECTOR}

For each of the selected sectors, adaptation actions for Turkey are listed [16]. In this paper, emphasis will only be given to the short-term actions, in other words, to the urgent actions to be implemented in the country. The list involves mitigation acts that are also common to most of the developing countries.

\section{A. Health}

- Realizing systematic monitoring and control of treated effluent during recycling and reuse applications for various purposes with the aim of guaranteeing human health,

- Increasing expertise related to infectious diseases,

- Strengthening monitoring mechanisms for animal (fauna) illnesses,

- Strengthening monitoring mechanisms for plant (flora) illnesses.

\section{B. Agriculture, Food Security, Forestry and Biodiversity}

- Applying modern irrigation systems with the least water loss on agricultural land, 
- Applying treated and biologically safe irrigation water on land,

- Calculating crop-based irrigation water need under different climatic conditions,

- Analysing economic vitality of agricultural policy under different climatic conditions,

- Encouraging farmers on the novelty of crop production (new products, new production techniques, etc.) via inspiring programs,

- Preventing water loss in drought prone land and forestry,

- Promoting cooperation among local and national forestry experts,

- Accepting forestry in-and-around cities as natural protection areas,

- Developing forest fire database and maintaining public accessibility to this database,

- Mapping sensitive areas regarding forest fires that might be expected especially during summer season,

- Activating protection areas (protection zones and bands),

- Evaluating protection areas under different climatic conditions,

- Evaluating different forest ecosystems regarding carbon balance.

\section{Water Resources}

- Collecting and storing rainwater for use as irrigation water,

- Reusing greywater after treatment for domestic and/or industrial purposes,

- Mapping regions where groundwater resources are sensitive to climate change,

- Mapping regions where surface water resources are sensitive to climate change,

- Examining management conditions of active groundwater resources.

\section{Infrastructure (Buildings, Transportation, Energy)}

- Taking protective measures towards minimizing water loss in the water transmission lines,

- Reducing probable flood risk in the sewage systems by realizing necessary modifications,

- Furnishing all the building couplings with irreversible valves,

- Using energy cables with thick cross-sections and maintaining their durability against strong winds,

- Developing vulnerability analysis approach for transportation network and structures (highway, railway, harbours and river structures),

- Re-arranging areas like airstrips and bridges,

- Strengthening the infrastructure of land, air and marine transportation, and mapping of these routes.

E. Superstructures (Urban and Watershed Planning, Buildings and Residential Sites)

- Developing construction materials and properties for different regions and locations according to various climatic conditions and to current local conditions,

- Applying heat insulation systems in the buildings to maintain cool conditions during summer and warm conditions during winter,

- Sustaining use of renewable energy resources in the buildings especially during winter time as air conditioning will not be sufficient in future,

- Placing sensitive species and general biodiversity during urban planning,

- Investigating common effects and risks of climate change during urban planning,

- Realizing insulation arrangements for keeping cool conditions in the buildings during summer.

\section{F. Coastal Areas}

- Revising probable climate change effects like sea level rise within the Coastal Risk Prevention Plan,

- Examining probable sea flows and effects of climate change on coastal areas,

- Developing morpho-dynamic and ecological response models of coastal units under different climatic conditions,

- Establishing monitoring systems and maintaining systematic data input to these systems,

- Supporting current coastal protection measures within the framework of adaptation actions,

- Projecting studies on coastal sensitivity (erosion, flood, etc.) till the end of the century,

- Calculating effects of sea level rise on the coastal residential sites,

- Preparing and applying management plans for each of the coastal area with different characteristics.

\section{G. Marine Environment and Fishery}

- Preparing and applying National Marine Strategy considering the adaptation policy of the country,

- Preparing renewal plans and long-term management actions with contribution of active participation and scientific means,

- Protecting production capacity of fish stocks,

- Establishing protection areas for the development of fish stocks durability,

- Forming monitoring systems for obtaining information on natural fish fauna,

- Assessing $\mathrm{pH}$ and carbon balance at coastal and marine regions,

- Setting environmental and ecological monitoring network,

- Mapping of vulnerable marine biodiversity,

- Developing external protection measures for threatened aquatic species.

\section{H. Tourism}

- Increasing perception on sustainable development by international nature walks at skiing centres,

- Preparing environmental impact assessment reports of climate change effects on tourism sector,

- Mapping of sensitive and critical regions under different climate change scenarios,

- Developing climate change indicator system,

- Developing management models for the fundamental adaptation actions.

\section{Industry-Commerce and Energy}

- Activating water saving methods during commercial activities and industrial production, 
- Using more effective cooling systems at power plants and stations,

- Establishing urgent water lines and connections for cooling systems at energy stations to be used during drought summer periods,

- Developing storm water systems at central energy plants for better removal of rainwater from the plants under extreme precipitation conditions,

- Establishing crisis task units to take rapid decisions under extreme weather conditions,

- In-plant water management, reusing treated effluent, separating dissolved elements that can be reused,

- Providing protective measures in the plants against extreme precipitation and overflows,

- Preparing emergency plans and necessary warning systems,

- Encouraging the use of renewable energy sources under different climate change scenarios,

- Assessing the impacts of different climate change scenarios on energy production plants consisting of air-cooled systems and on water resources,

- Determining additional energy need due to climate change at regional level and at sectoral based situation.

\section{J. Research and Development}

- Conducting fundamental research for maintaining biological control of pathogenic organisms,

- Determining risk causing pathogens and conducting research on their characterization by international studies at the global scale,

- Developing laboratory methods to enhance the definition of contaminated blood and organs and infected humans,

- Developing new curing products, injections and injection methodologies,

- Analysing infections passing through the food chain,

- Developing and recommending protective health policies related to health problems, high temperature and climate change,

- Investigating ecosystem viability and adaptation to climate change,

- Predicting climate observations and models at yearly or 10-year interval basis,

- Regionalizing global climate projections,

- Investigating future socio-economic fluctuations,

- Evaluating indoor air quality at the existing buildings in terms of health and conducting new studies for energy efficiency in these buildings,

- Examining mangrove wetlands and coral reefs proving natural protection against coastal erosion,

- Combining adaptation targets with research programs against climate change.

\section{$K$. Informing, Training and Education}

- Informing and increasing public awareness of society on the effects of climate change,

- Forming a communication network among related experts in charge of climate change adaptation policies,

- Encouraging and introducing the use of suitable irrigation infrastructures,

- Guiding crop producers (farmers) on the development of appropriate crop types,

- Informing shareholders and public on the results and monitoring of climate change in order to increase consciousness and awareness on the necessity of adaptation measures,

- Providing effective information on animal health, animal feeding and on livestock breeding,

- Increasing public awareness on the health effects of climate change and providing participation on adaptation activities at community level,

- Informing public on water related diseases and health, determining risk groups,

- Introducing the protection methods/ways from emerging infections based on climate sensitive pathogens,

- Preparing annual agricultural research programs related to climate change effects and adaptation actions and maintaining accessibility to these information from internet,

- Supporting cooperation among farmers and facilitating information flow,

- Introducing effective water use technologies in agriculture,

- Deciding on the most proper communication approach and language to be used with public,

- Preparing an official website or portal on 'Adaptation to Climate Change'

- Arranging a mobile exhibition travelling around the country informing public on 'Adaptation to Climate Change'

- Arranging open to public activities on climate change and its effects,

- Renewing communication sources, and especially concentrating on visual communication,

- Compiling summaries of scientific data,

- Setting internet web sites to disseminate updated information,

- Raising awareness of policy makers,

- Introducing adaptation policies and methodologies to public offices,

- Demonstrating success stories regarding best applications,

- Furnishing accessible education and training sources among education communities (teachers and students),

- Training society, environmental and occupational health experts on sustainable development especially under climate change conditions,

- Training those groups interested in setting up new business in various fields as probable effects of climate change may lead to such new business areas,

- Introducing and encouraging livestock breeding and management,

- Raising consumer awareness by ecological (eco-certification) certification.

\section{Financing and Insurance}

- Effective management of opportunities and probable risks that may arise with climate change so as the banks and insurance companies may do investments,

- Ensuring the reliability of risk models used to guarantee financial stability of banks and insurance companies 
together with central and regional control authorities,

- Communicating on the climate change risks and opportunities by utilizing advanced training programs and effective correspondence in the investment field,

- Communicating of the central government with banks and insurance companies, shareholders, academicians and non-profit organizations,

- Protecting farmers by developing insurance mechanisms against climate change,

- Forming investment trust for paying compensation to the farmers in case of any animal/plant illness, infection or an environmental disaster,

- Preventing foresters from being affected by a climate-oriented disaster through developing insurance system,

- Preparing a database on the effective use of resources targeting adaptation,

- Accelerating studies on finding additional financial resource,

- Developing adaptation encouragement mechanisms for citizens,

- Developing insurance system by the help of preventive policies,

- Conducting risk assessment according to various climatic conditions in different insurance branches,

- Developing special models for insurance sector,

- Introducing and disseminating insurance tools.

\section{COMMON TOPICS AMONG SECTORS (INTERSECTING SECTORS)}

As can be seen from the list of urgent adaptation actions under each of the selected sectors, many proposed activities are common to more than one sector. Three actions come forward in almost all the sectors: more research is needed under each sector, raising awareness of the public on the importance of each sector, and finally the necessity to provide additional budget to promote the application of the listed actions.

A few examples of the intersecting sectors are given below.

- Agriculture, Food Security, Forestry and BiodiversityHealth- Water Resources

- Health- Coastal Areas-Marine Environment and FisheryTourism

- Infrastructure-Superstructure-Health-Coastal Areas

- Industry, Commerce and Energy- Infrastructure

- Industry, Commerce and Energy - Superstructure

Based on the complex structure of the sectors, it becomes so important and compulsory that all the related state offices and private sector together with public and NGO's are supposed to work in coordination directed by the Ministries. This collaboration must be prioritized in Turkey representing a developing country. As an initial step towards coping with the climate change effects, such countries need to increase their capacity building and other related adaptation structures both at local and national scales.

\section{CONCLUSIONS AND RECOMMENDATIONS}

The main target of selecting and listing the main sectors with the purpose of preparing the climate change adaptation actions is an essential step for a country towards mitigating with climate change effects. Prioritization of sectors and listing the related urgent, short and long-term activities will differ from country to country based on various factors as mentioned in this article. The second important stage to be followed is to conduct the cost/benefit analysis of each of the listed actions under different sectors prior to realizing the referred actions. Therefore, for Turkey, representing a developing country, the main sectors under which adaptation actions is listed need to be further analysed at watershed scale.

25 watersheds of the country are initially grouped as coastal watersheds and inner watersheds. 12 key sectors are selected in general. However, 2 of the sectors; coastal areas and marine environment and fishery sectors will not of concern in the inner ones. Passing into action; in other words, application of the proposed urgent actions listed for all the 12 sectors is of utmost importance which constitute the core of this study. They need to be practiced in a planned manner with care. Another significant concern is that each of the 25 watersheds has its specific problems and properties; even the neighbourhood ones may bear different characteristics. As such, detailed vulnerability analysis must be conducted for each of the watershed regarding the sectors and related prioritized actions stated underneath.

The list of adaptation activities that need to be foreseen and monitored is given below. As can be recognized, the approach undertaken resembles preparing a master plan.

- Sectoral vulnerability study on the proposed sectors (field surveys and preparing detailed inventory),

- Determination of adaptation activities based on the outcomes of sectoral vulnerability analyses, prioritization of actions,

- Planning of sector-based adaptation activities,

- Completing cost/benefit analyses of the planned adaptation activities,

- Preparation of budget required according to the results of cost/benefit analyses,

- Realization of activities,

- Receiving feedback from the applied adaptation activities and if necessary revising the activities.

Turkey is now conducting field studies and surveys to accomplish detailed inventory of each of the watersheds. In some of the watersheds, vulnerability analyses were realized under some of the priority sectors. These analyses will be carried out for all the watersheds. It is then that adaptation activities will be based on the results of the vulnerability analyses for each of the watersheds separately.

This study determines the main sectors under which vulnerability analysed should be based upon a thorough investigation of the status of 7 other countries of the world. The urgent adaptation actions towards climate change effects are listed under each of the selected sectors with the purpose of initiating such studies to the public and to the administrative authorities.

\section{REFERENCES}

[1] Climate Risk Case Study, Pilot Climate Change Adaptation Market Study: Turkey, International Finance Corporation and European Bank of Reconstruction and Development, 2013. 
[2] Climate Change Adaptation - Related Indicators, ER23 Final Report, July 2012.

[3] Intergovernmental Panel on Climate Change (IPPC), $4^{\text {th }}$ Assessment Report (AR4), Working Group II Report, Impacts, Adaptation and Vulnerability, 2007.

[4] H. M, Füsell and R. J. T. Klein, "Climate change vulnerability assessments: an evolution of conceptual thinking," Climatic Change, vol. 75, pp. 301-329, 2006.

[5] S. Isoard, T. Grothmann, and M. Zebisch, "Climate change impacts, vulnerability and adaptation: theory and concepts,"Workshop on Climate Change Impacts and Adaptation in the European Alps: Focus Water, 2008, UBA Vienna.

[6] Global Warming-Climate Change and Effects on Turkey. [Online]. Available: https://www.isu.gov.tr/icerik/detay.aspx?Id=335

[7] Climate Policy Observer. In Depth: A tangled case-Turkey's status under UNFCCC and the Paris Agreement. [Online]. Available: http://climateobserver.org/tangled-case-turkey-status-unfccc-paris-agr eement/

[8] Turkish Statistical Institute. [Online]. Available: http://www.turkstat.gov.tr/PreHaberBultenleri.do?id=24588

[9] OECD, OECD Economic Surveys: Turkey 2016, OECD Publishing, Paris, 2016.

[10] United Nations Climate Change Conference and Turkey. [Online]. Available:

http://www.bbc.com/turkce/ekonomi/2015/11/151130_cop21_turkiye cuneyt_kazokoglu

[11] United Nations Climate Change Conference, Paris 2015. [Online]. Available: http://www.un.org/sustainabledevelopment/cop21/

[12] M. Tayanc, U. Im., M. Dogruel, and M. Karaca, "Climate change in Turkey for the last half century," Climatic Change, vol. 94, issue 3-4, pp. 483-502, 2009.

[13] B. Onol and Y. Unal, "Assessment of climate change simulations over climate zones of Turkey," Regional Environmental Change, vol. 14, no. 5, pp. 1921-1935, 2014.

[14] E. Turhan, S. C. Mazlum, U. Sahin, and A. H. Sorman, "Beyond special circumstances: climate change policy in Turkey 1992-2015," Wiley Interdisciplinary Reviews: Climate Change, vol. 7, no. 6, pp. 448-460, 2016

[15] A. Tanik and D. Tekten, "Climate change adaptation practices in various countries," in Proc. 2nd International Conference on Green Energy Technology, Rome, Italy, IOP Conference Series: Earth and Environmental Science, 83, 012027, pp. 1-9, July 2017.

[16] D. Tekten, "Sectoral-based adaptation proposals against climate change for Turkey," M.Sc. dissertation, Graduate School of Science, Technology and Engineering, Istanbul Technical University (ITU), Istanbul, 2016.

[17] S. Curtis, A. Fair, J. Wistow, D. V. Val, and K. Oven, "Impact of extreme weather events and climate change for health and social care systems," Environmental Health, vol. 16, suppl. 1:128, pp. 23-32, 2017.

[18] C. Cook, "Climate change and health: nurses as drivers of climate action," Interdisciplinary Journal of Partnership Studies, vol. 5, issue 1, Article 8, 2018

[19] FAOSTAT. [Online]. http://www.fao.org/faostat/en/\#country/223

[20] Climate Change Impacts on Water Resources Project. [Online] Available: http://iklim.ormansu.gov.tr/Eng/

[21] P. Baum and C. Davies. (2017). Climate change: A global challenge for infrastructure. [Online]. Available: http://www.ebrd.com/news/2017/climate-change-a-global-challenge-f or-infrastructure.html

[22] T. Matthews, A. Y. Lo, and J. A. Byrne, "Re-conceptualizing green infrastructure for climate change adaptation: Barriers to adoption and drivers for uptake by spatial planners," Landscape and Urban Planning, vol. 138, pp. 155-163, 2015.
[23] M. Demuzere, K. Orru, O. Heidrich, E. Olazabal, D. Geneletti, H. Orru, A.G. Bahave, N. Mittal, E. Feliu, and M. Faehnle, "Mitigating and adapting to climate change: Multi-functional and multi-scale assessment of green urban infrastructure," Journal of Environmental Management, vol. 146, pp. 107-115, 2014.

[24] U. Beck, The Metamorphosis of the World, $1^{\text {st }}$ edition: U. K.: Wiley 2016, Part II: Themes.

[25] B. Castelle, G. Dodet, G. Masselink, and T. Scott, "A new climate index controlling winter wave activity along the Atlantic coast of Europe: The West Europe pressure anomaly," Geophysical Research Letters, vol. 44, no. 3, 2017, pp. 1384-1392.

[26] S. Fatoric, R. Moren-Aegret, R. J. Niven, and G. Tan, "Living with climate change risks: Stakeholders' employment and coastal relocation in mediterranean climate regions of Australia and Spain," Environment Systems and Decisions, vol. 37, no. 3, 2017, pp. 276-288

[27] S. Rahmstorf, "Rising hazard of storm-surge flooding," PNAS, Proceedings of the National Academy of Sciences of the United States of America, 2017, vol. 114, no. 45, pp. 11806-11808.

[28] A. J. Garner, M. E. Mann, K. A. Emanuel, R. E. Kopp, N. Lin, R. B. Alley, B. P. Horton, R. M. DeConto, J. P. Donnelly, and D. Pollard, "Impact of climate change on New York City's coastal flood hazard Increasing flood heights from the preindustrial to $2300 \mathrm{CE}$," PNAS, in Proc. the National Academy of Sciences of the United States of America, 2017, vol. 114, no. 45, pp. 11861-11866.

[29] S. Tjossem, "Developing unified marine climate change research," Fostering Internationalism through Marine Science, Springer: Cham, 2017, pp. $123-150$

[30] P. A. Woodworth-Jefcoats, J. J. Polovina, and J. C. Drazen, "Climate change is projected to reduce carrying capacity and redistribute species richness in North Pacific pelagic marine ecosystems," Global Change Biology, vol. 23, no. 3, 2017, pp. 1000-1008.

[31] B. Amelung, S. Nicholls, and D. Viner, "Implications of global climate change for tourism flows and seasonality," Journal of Travel Research, vol. 45, no. 3, 2007, pp. 285-296.

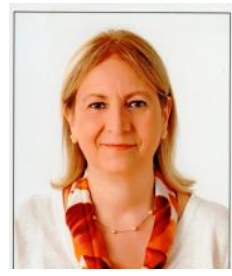

Aysegul Tanik was born in London in 1958. She obtained her B.Sc. degree in chemical engineering (1981) and the M.Sc. degree (1984) in environmental engineering from Bogazici University, Istanbul. Her Ph.D. is in environmental engineering (1991) and she got her degree from ITU, Faculty of Civil Engineering, Dpt. of Environmental Engineering where she has been a member of teaching staff since 1992

She has become associate professor in 1996 and full professor in 2002. She has worked as a project and research engineer in various contracting firms dealing with treatment of water and wastewater within the years 1984-1992. Her current fields of interest are; water quality management, water quality modeling, and integrated watershed management.

Prof. Tanik has 75 papers appearing in international SCI journals and more than 70 papers in the selected international proceedings besides many national conference papers.

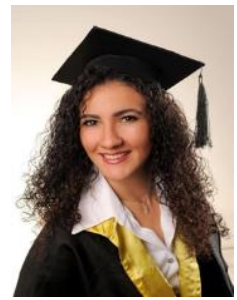

Deniz Tekten was born in İstanbul in 1990. She obtained her B.Sc. degree in environmental engineering (2014) from Istanbul University and the M.Sc. degree (2016) from the Graduate School of Science, Technology and Engineering of Istanbul Technical University (ITU).

Upon her graduation from ITU, she worked a environmental engineer in different private firms. Currently, she is working as health and safety specialist at Greif FPS Turkey. This article is derived partly from her M.Sc. dissertation. 